\title{
Difference in protective effects of GIP and GLP-1 on endothelial cells according to cyclic adenosine monophosphate response
}

\author{
DONG-MEE LIM ${ }^{1}$, KEUN-YOUNG PARK ${ }^{1}$, WON-MIN HWANG ${ }^{2}$, JU-YOUNG KIM ${ }^{3}$ and BYUNG-JOON KIM ${ }^{4}$ \\ Divisions of ${ }^{1}$ Endocrinology and ${ }^{2}$ Nephrology, Department of Internal Medicine, Konyang University School of Medicine, \\ Daejeon 35365; ${ }^{3}$ Imaging Science-Based Lung and Bone Diseases Research Center, Wonkwang University, \\ Iksan, Jeonbuk 54538; ${ }^{4}$ Division of Endocrinology, Department of Internal Medicine, \\ Gachon University School of Medicine, Incheon 21565, Republic of Korea
}

Received November 5, 2015; Accepted December 19, 2016

DOI: $10.3892 /$ etm.2017.4279

\begin{abstract}
Receptors for glucose-dependent insulinotropic polypeptide (GIP) and glucagon-like peptide 1 (GLP-1) are present in vascular endothelial cells. Previous studies investigating euglycemic status have demonstrated that GIP is directly involved in the physiology of blood vessels by controlling the blood flow rate of portal veins and that GLP-1 has a protective effect on blood vessels by acting on endothelial cells. However, to the best of our knowledge, the effects of GIP and GLP-1 on endothelial cells in patients with hyperglycemia remain unknown. Therefore, the present study investigated whether the effect of the incretin hormones GLP-1 and GIP differed with regards to the reversal of endothelial cell dysfunction caused by hyperglycemia. The production of nitric oxide (NO) was measured using the Griess reagent system kit and the expression of cyclic adenosine monophosphate (cAMP) in the cell was measured at a wavelength of $405 \mathrm{~nm}$ with the ELISA reader using the cyclic AMP EIA kit. Exposure of human umbilical vein endothelial cells (HUVEC) to a high glucose concentration decreased NO and endothelial nitric oxide synthase (eNOS) levels but increased inducible NOS (iNOS) levels. However, when HUVECs were pretreated with GLP-1, a reduction of iNOS expression was observed and the expression of eNOS and NO were increased, as opposed to pretreatment with GIP. The results differed according to the response of cAMP, the second messenger of incretin hormones: The GIP pretreatment group did not exhibit an increase in cAMP levels while the GLP-1 pretreatment group did. The results of the present study
\end{abstract}

Correspondence to: Professor Byung-Joon Kim, Division of Endocrinology, Department of Internal Medicine, Gachon University School of Medicine, 786 Namdong-daero, Namdong-gu, Incheon 21565, Republic of Korea

E-mail: kbjoon4u@hananet.net

Key words: cyclic adenosine monophosphate response, glucosedependent insulinotropic polypeptide, glucagon-like peptide 1, nitric oxide provide evidence that GLP-1, but not GIP, has a protective effect on endothelial function associated with cardiovascular disease, as it is associated with increased eNOS expression and the levels of NO. This effect may be due to an increase in the cAMP concentration during hyperglycemic events.

\section{Introduction}

Hyperglycemic conditions evoked by diabetes mellitus disrupt the role of endothelial cells in the protection of blood vessels and is therefore associated with cardiovascular disease. Diabetic macrovascular complications, such as myocardial infarction and stroke, are a major cause of morbidity and mortality (1). Once atherosclerosis has developed, it is irreversible and the progression of endothelial damage continues. Thus, even if blood sugar levels are well controlled thereafter, the natural course of macrovascular complications cannot be altered (2). In early stage diabetes mellitus, nitric oxide (NO), an endothelium-derived relaxing factor, is important in relaxing and protecting the blood vessels. NO is produced as a result of an enzymatic reaction of the L-arginine amino acid, facilitated by nitric oxide synthase (NOS). Endothelial cells possess two forms of NOS: Constitutive or endothelial NOS (cNOS or eNOS; type III) and inducible NOS (iNOS; type II) (3). Under normal conditions, NO has anti-inflammatory and anti-proliferative effects, which protect blood vessels by inhibiting smooth muscle hyperplasia and scavenging superoxide anion. NO also inhibits leukocyte adhesion to vascular endothelium, exerting an anti-thrombotic effect (3). However, abnormal conditions, such as inflammation and hyperglycemia, lead to a decrease in the synthesis of NO. This may lead to the development of vascular diseases including inflammation, thrombosis, vascular hypertrophy, stenosis and vasoconstriction (4).

Diabetic vascular complications are caused by endothelial cell dysfunction. Initially, the damage caused by lesions is reversible (4), thus early treatment to correct endothelial dysfunction is important to prevent diabetic macrovascular complications, and reduce the morbidity and mortality caused by cardiovascular diseases (5).

Incretin hormones, such as glucose-dependent insulinotropic polypeptide (GIP) and glucagon-like peptide-1 (GLP-1), 
have become the subjects of attention. GIP and GLP-1 are intestinal hormones that control blood sugar by stimulating insulin release from the pancreas (6). Incretin hormones have receptors in a number of organs and have been assessed with regards to control of blood sugar levels (7). GIP and GLP-1 receptors are present in vascular endothelial cells. It has been demonstrated that GIP is directly involved in the physiology of blood vessels; controlling the blood flow rate of the hepatic portal veins and increasing nutrient absorption (8). GLP-1 has a protective effect on blood vessels by acting on the endothelial cells (9). However, to the best of our knowledge, the current data do not sufficiently clarify the effects that GIP and GLP-1 have on endothelial cells in patients with hyperglycemia.

Therefore, the present study aimed to investigate whether the incretin hormones GLP-1 and GIP improve endothelial cell dysfunction caused by hyperglycemia.

\section{Materials and methods}

Cell culture and treatments. Hamster-derived insulinsecreting HIT-T15 cells (Calbiochem; EMD Millipore, Billerica, MA, USA) were maintained in RPMI 1,640 medium (Gibco; Thermo Fisher Scientific, Inc., Waltham, MA, USA) containing $11.1 \mathrm{mM}$ glucose supplemented with $10 \%$ heat-inactivated fetal bovine serum (Gibco; Thermo Fisher Scientific, Inc.), penicillin $(100 \mathrm{U} / \mathrm{ml})$, and streptomycin $(100 \mu \mathrm{g} / \mathrm{ml})$, in a humidified atmosphere containing $5 \% \mathrm{CO}_{2}$ at $37^{\circ} \mathrm{C}$. These cells were used as a comparison when determining whether GIP and GLP-1 were expressed in HUVECs.

Passage 6-10 cells of human umbilical vein endothelial cells (HUVECs) supplied by Lonza (Walkersville, MD, USA) were cultured with medium from the EGM-2 ${ }^{\mathrm{TM}}$ Bullet kit ${ }^{\mathrm{TM}}$ (Lonza). The kit contained $10 \%$ fetal bovine serum, vascular endothelial growth factor, human fibroblastic growth factor B, hydrocortisone, R3-insulin-like growth factor-I, ascorbic acid, GA-1,000, human epidermal growth factor and heparin. The conditions for culture were maintained at $37^{\circ} \mathrm{C}$ and $95 \%$ humidity in $5 \%$ $\mathrm{CO}_{2}$. When the confluence reached $80-90 \%$, subcultures were prepared following washing with phosphate-buffered saline (PBS) and processing with trypsin-EDTA. The collected cells were underwent centrifugation at room temperature, $500 \mathrm{xg}$ for $10 \mathrm{~min}$ in order to produce pellets. The pellets were gently resuspended in EGM-2 ${ }^{\mathrm{TM}}$ Bullet $\mathrm{kit}^{\mathrm{TM}}$ medium once the supernatant was discarded. This medium was replaced every 2 days until confluence was reached (3-5 days). Following treatment with GIP (Sigma-Aldrich, Merck kGaA, Darmstadt, Germany), GLP-1 (Bachem Americas, Inc., Torrance, CA, USA), or Exendin 9-39, a specific GLP-1 receptor antagonist (Bachem Americas) in 5.5 or $30 \mathrm{mM}$ glucose, analysis was completed. Exendin 9-39 GLP-1 receptor antagonist (Saxon Biochemicals, Hannover, Germany) was used to determine if the change in iNOS and eNOS was due to the GLP-1 receptor agonist. HUVECs were pretreated for $1 \mathrm{~h}$ with $1 \mathrm{nM}$ GIP or $3 \mathrm{nM}$ GLP-1, and $50 \mu \mathrm{M}$ DPPIV inhibitor (Sigma-Aldrich; Merck kGaA, Darmstadt, Germany). HUVECs were then cultured in medium containing 5.5 or $30 \mathrm{mM}$ glucose for $48 \mathrm{~h}$.

RNA extraction and reverse transcription-polymerase chain reaction $(R T-P C R)$. RT-PCR was used to determine the presence of GIP or GLP-1 receptors in HUVECs. Total
RNA was extracted using TRIzol ${ }^{\circledR}$ reagent (Invitrogen; Thermo Fisher Scientific, Inc.) following the manufacturer's protocol. The reverse transcription reaction was completed at $42^{\circ} \mathrm{C}$ for $60 \mathrm{~min}$ using ImProm-II ${ }^{\mathrm{TM}}$ reverse transcription system (20 $\mu \mathrm{l}$; Promega Corporation, Madison, WI, USA), containing AMV reverse transcriptase, $\mathrm{MgCl}_{2} 25 \mathrm{mM}$, reverse transcription $10 \mathrm{X}$ buffer, dNTP mixture $10 \mathrm{mM}$, recombinant $\mathrm{RNa}$ in ribonuclease inhibitor and oligo $(\mathrm{dT})_{15}$ primer, before heating them to $70^{\circ} \mathrm{C}$ for $5 \mathrm{~min}$ followed immediately by cooling on ice so that reverse transcription enzymes were inactivated and cDNA remained in a linear strand state. cDNA $(1 \mu \mathrm{g})$ was amplified in final volume $20 \mu \mathrm{l}$ with iTaq $^{\mathrm{TM}}$ DNA polymerase (Bio-Rad Laboratories Inc., Hercules, CA, USA) using the following primer sets: GIP receptor: Forward, 5'-AACGAAGTCAAGGCCATTTG-3' and reverse, 5'-GTCCTCAGCTTGGACAGGAG-3'; GLP-1 receptor: Forward 5'-GTTCCCCTGCTGTTTGTTGT-3' and reverse, 5'-TGGCCTTCAGTTTGGATACC-3'; GAPDH forward, 5'-AAGGGTCATCATCTCTGCCC-3' and reverse, 5'-GTGATGGCATGGACTGTGGT-3'. PCR reaction procedure began with heating at $95^{\circ} \mathrm{C}$ for 5 min prior to cycle starts. Cycles consisted of denaturation at $94^{\circ} \mathrm{C}$ for $30 \mathrm{sec}$, annealing at $55^{\circ} \mathrm{C}$ for $30 \mathrm{sec}$ and elongation at $72^{\circ} \mathrm{C}$ for $30 \mathrm{sec}$, repeated 30 times, followed by the extension of generated strands at $72^{\circ} \mathrm{C}$ for $5 \mathrm{~min}$. Following the PCR reaction process, the extended DNA was subjected to electrophoresis at $100 \mathrm{~V}$ for 20 min using $1.2 \%$ agarose gel.

Reverse transcription-quantitative PCR (RT-qPCR). Extraction of total RNA and cDNA synthesis were performed using the aforementioned method in the previous section. RT-qPCR primers were synthesized, 100 bps based on the base sequence of GenBank (https://www.ncbi.nlm.nih. gov/genbank). Sequences of the synthesized primers were as follows: iNOS, forward, 5'-ACA AGCCTACCCCTC CAGAT-3' and reverse, 5'-TCCCGTCAGTTGGTAGGT TC-3'; eNOS, forward, 5'-CCCTTCAGTGGCTGGTACAT-3' and reverse 5'-TATCCAGGTCCATGCAGACA-3'; GAPDH, forward 5'-AAGGGTCATCATCTCTGCCC-3' and reverse 5'-GTGATGGCATGGACTGTGGT-3'. qPCR was performed with a $20 \mu \mathrm{l}$ reaction mixture containing $1 \mu \mathrm{g}$ cDNA, 10 pmol forward primer, 10 pmol reverse primer and $10 \mu \mathrm{l}$ Fast SYBR Green Master Mix (Invitrogen; Thermo Fisher Scientific, Inc.) using the $\mathrm{iQ}^{\mathrm{TM}} 5$ Optical system (Bio-Rad Laboratories, Inc.). The reaction procedure was completed as follows: Heating at $95^{\circ} \mathrm{C}$ for $5 \mathrm{~min}$ prior to denaturation at $95^{\circ} \mathrm{C}$ for $30 \mathrm{sec}$, annealing at $60^{\circ} \mathrm{C}$ for $30 \mathrm{sec}$ and elongation at $72^{\circ} \mathrm{C}$ for $30 \mathrm{sec}$ for 40 cycles. This was followed by the extension of generated strands at $72^{\circ} \mathrm{C}$ for $5 \mathrm{~min}$. Melting curve analysis was performed at a temperature between $65-95^{\circ} \mathrm{C}$ and a $\mathrm{Cq}$ value for each was used to normalize the data to GAPDH mRNA value following compensation (10).

Western blot analysis. Cells were harvested and then pelleted by centrifugation at $13,000 \mathrm{rpm}$ for $10-20 \mathrm{sec}$. Cells were resuspended in $400 \mu \mathrm{l}$ PRO-PREP ${ }^{\mathrm{TM}}$ solution (Intron Biotechnology, Inc., Seongnam, Korea), and mix well. Cell lysis was induced by incubation for $10-20 \mathrm{~min}$ on freezer at $-20^{\circ} \mathrm{C}$. Centrifugation was then performed at $2,000 \mathrm{x} \mathrm{g}$ at $4^{\circ} \mathrm{C}$ for $5 \mathrm{~min}$, and supernatant was transferred to a fresh $1.5 \mathrm{ml}$ tube. 
The extracted protein was quantified using a Bradford protein assay kit (Bio-Rad Laboratories, Inc.) and equal amounts of protein $(20 \mu \mathrm{g} /$ lane) were separated by $20 \%$ SDS-PAGE and transferred to a nitrocellulose membrane (Invitrogen; Thermo Fisher Scientific, Inc.). The membrane was incubated in 5\% non-fat dry milk-PBS Tween-20 (PBST; $0.01 \%$ Tween 20 in PBS) for $1 \mathrm{~h}$ at room temperature to block the non-specific bonding between antibody and protein. Primary antibodies; anti-iNOS (sc-49055; Santa Cruz Biotechnology, Inc., Dallas, TX, USA), anti-eNOS (9572; Cell Signaling Technology, Inc., Danvers, MA, USA), anti-phospho-eNOS (Ser1177) (9517; Cell Signaling Technology, Inc.), anti-GIP receptor (ab30679; Abcam, Cambridge, UK), anti-GLP-1 receptor (ab36598; Abcam) and anti- $\beta$-actin (internal control; a5441; Sigma-Aldrich; Merck kGaA) were incubated with the protein at room temperature for $2 \mathrm{~h}$ (anti- $\beta$-actin was diluted to 1:5,000 and other antibodies to 1:500 with blocking buffer). Following washing with PBST twice for $10 \mathrm{~min}$, the secondary antibodies, anti-mouse immunoglobulin (Ig) G (sc-51993) and anti-rabbit IgG (sc-358919; Santa Cruz Biotechnology, Inc.) conjugated with horseradish peroxidase (HRP) were diluted to 1:500 with blocking buffer and incubated at room temperature for $1 \mathrm{~h}$. The protein obtained following the reaction was examined for specific bands following exposure to light on X-ray film using the Chemiluminescent Reagent kit (ab79907; Abcam).

MTT assay. An MTT assay (Vybrant ${ }^{\circledR}$ MTT Cell Proliferation Assay kit, Invitrogen; Thermo Fisher Scientific, Inc.) was completed.

Assessment of NO production. The activity of NO was determined by measuring the nitrite $\left(\mathrm{NO}_{2}-\right)$ concentration in the culture media using the Griess reagent system (Promega Corporation). Each medium supernatant $(100 \mathrm{ml})$ was mixed with $50 \mathrm{ml} 1 \%$ sulfanilamide (in $5 \%$ phosphoric acid, Sigma-Aldrich; Merck kGaA) and $50 \mathrm{ml}$ 0.1\% N-(1-Naphthyl) ethylenediamine dihydrochloride (Santa Cruz Biotechnology, Inc.) and incubated in the dark at room temperature for $10 \mathrm{~min}$. Absorbance was measured using a SpectraMax L Microplate Reader (Molecular Devices, LLC, Sunnyvale, CA, USA) at $540 \mathrm{~nm} . \mathrm{NO}_{2}$ concentration was determined based on the nitrogen standard curve.

Measurement of cyclic adenosine monophosphate (cAMP). Cultured cells were washed with cold PBS twice and lysed with $0.1 \mathrm{M}$ hydrochloric acid at room temperature for $20 \mathrm{~min}$. Cells were then collected using a scraper and subjected to centrifugation at $1,000 \mathrm{x} \mathrm{g}$ for $10 \mathrm{~min}$ at room temperature. The supernatant was transferred to new tubes and used for experimentation in a 96-well plate. cAMP levels in the cells were measured at a wavelength of $405 \mathrm{~nm}$ using an ELISA microplate reader (Molecular Devices LLC.) using a cyclic AMP ELISA kit (581001; Cayman Chemical Company, Ann Arbor, MI, USA) according to the manufacturers protocol.

Statistical analysis. Each experiment was repeated four times and data were indicated as mean \pm standard deviation. All statistical analysis was performed using the Statistical Package for the Social software (SPSS; Korean version 20.0; IBM SPSS, Armonk, NY, USA). Statistical differences were
A
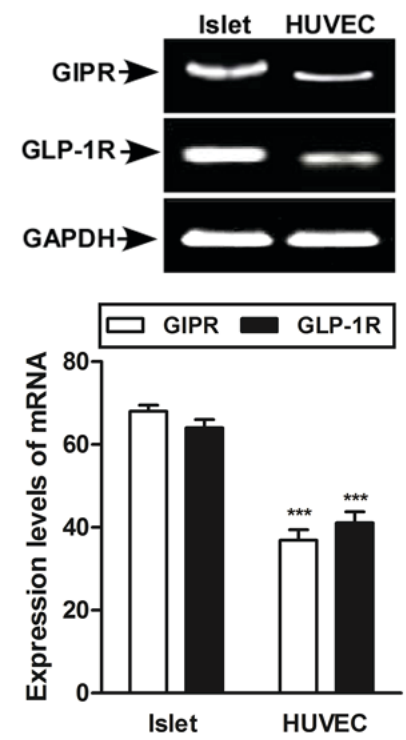

Figure 1. Expression of GIPR and GLP-1R mRNA in HUVECs using reverse transcription-polymerase chain reaction and western blot analysis. (A) mRNA expression of GIP and GLP-1 receptors present in HUVEC and (B) protein expression level of GIP and GLP-1 receptors present in HUVEC is lower than in islet cells. GAPDH and $\beta$-actin were used as controls. Data are presented as mean \pm standard deviation. ${ }^{* * *} \mathrm{P}<0.001$ vs. control cells, GIP, glucose-dependent insulinotropic polypeptide; GLP-1, glucagon-like peptide 1; HUVEC, human umbilical vein endothelial cells; GIPR, GIP receptor; GLP-1R, GLP-1 receptor.

analyzed using one-way analysis of variance followed by Tukey's test. $\mathrm{P}<0.05$ was determined to indicate a statistically significant difference.

\section{Results}

Expression of GIP and GLP-1 receptors in HUVEC. Prior to investigating the action of GIP or GLP-1 in endothelial cells, RT-PCR and western blot analysis were used to assess whether GIP and GLP-1 receptors were expressed in HUVEC. The expression of GIP and GLP-1 receptors in HUVECs is lower than in islet cells (Fig. 1A). Furthermore, in HUVEC cells, the GLP-1 receptor is more highly expressed than the GIP receptor (Fig. 1B). Islet cells were used as positive control. An MTT assay was completed to eliminate cell death from high glucose. During the low and high glucose exposure for up to $48 \mathrm{~h}$, the HUVECs survived and the maintenance of cell morphology was confirmed by MTT and light microscopy (data not shown).

Effect of high glucose on iNOS and eNOS mRNA expression and NO production. To compare NOS expression against high glucose levels, expression of iNOS mRNA and eNOS mRNA were measured by RT-qPCR. The expression of iNOS and eNOS mRNA was not affected in normal conditions with $5.5 \mathrm{mM}$ glucose (Fig. 2A). However, the expression of eNOS mRNA significantly decreased by $>50 \% 12 \mathrm{~h}$ following treatment with $30 \mathrm{mM}$ glucose, indicating a fast reaction $(\mathrm{P}<0.001$; Fig. 2B). Following treatment with $30 \mathrm{mM}$ glucose, the expression of iNOS mRNA did not increase during the initial 


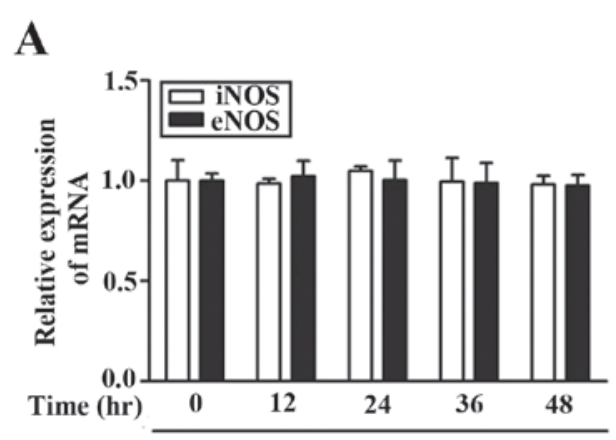

Glucose $5.5 \mathrm{mM}$

C

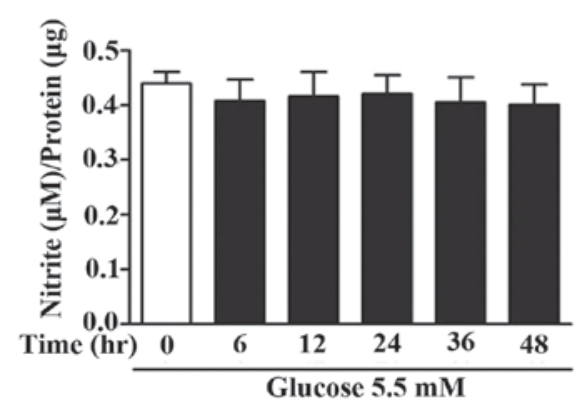

B

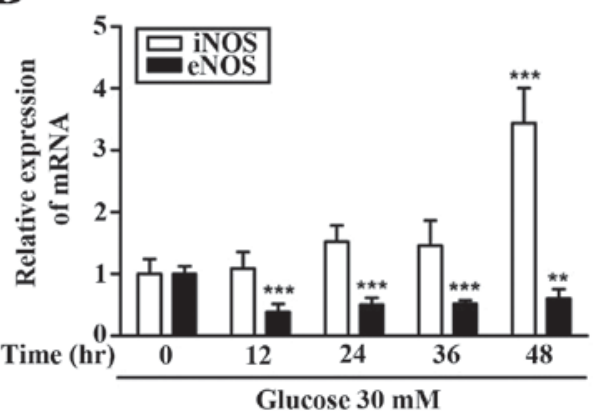

D

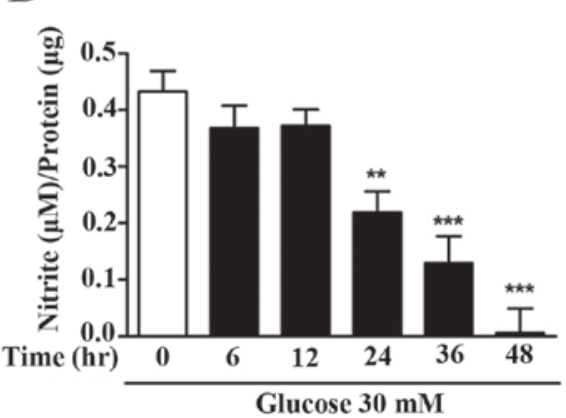

Figure 2. Time-dependent analysis of iNOS, eNOS and NO in low and high-glucose conditions. Expression of iNOS and eNOS in (A) 5.5 and (B) 30 nM glucose determined by reverse transcriptase-quantitative polymerase chain reaction. Activity of nitric oxide with (C) 5.5 and (D) $30 \mathrm{nM}$ glucose examined by Griess reagent system kit. Data are presented as the means \pm standard deviation of six independent experiments. ${ }^{* *} \mathrm{P}<0.01,{ }^{* * *} \mathrm{P}<0.001$ vs. control cells. iNOS, inducible nitric oxide synthase; eNOS, endothelial nitric oxide synthase; NO, nitric oxide.

0-36 h but significantly increased compared with the baseline value following $48 \mathrm{~h}(\mathrm{P}<0.01$; Fig. $2 \mathrm{~B})$. The production of nitric oxide, which is associated with vascular endothelial cell function, was not affected in normal conditions with $5.5 \mathrm{mM}$ glucose (Fig. 2C) but decreased significantly from $24 \mathrm{~h}$ onwards under the high glucose $(30 \mathrm{mM})$ condition $(\mathrm{P}<0.01$; Fig. 2D).

Effects of GIP or GLP-1 on the expression of iNOS and eNOS and the production of NO in high glucose concentrations. Similar to the results described in Fig. 2, a high glucose concentration $(30 \mathrm{mM})$ had different effects on eNOS and iNOS in HUVEC and led to a decrease in NO production. In order to determine whether incretin hormones have a protective effect on the reaction of endothelial cells to hyperglycemia, the experiment was performed following treatment with GIP or GLP-1. HUVECs pre-treated with GLP-1 exhibited decreased expression of iNOS mRNA $(\mathrm{P}<0.01)$ and an increase in eNOS mRNA expression under hyperglycemic conditions (both $\mathrm{P}<0.001$; Fig. 3A). However, HUVECs pre-treated with GIP did not exhibit any change in iNOS and eNOS mRNA expressions (Fig. 3A). Similar results were obtained regarding the expression of iNOS and eNOS protein (Fig. 3B). The production of NO also differed between these two treatment groups, demonstrating a significant increase of NO expression in the GLP-1 treatment group compared with control group $(\mathrm{P}<0.001$; Fig. 3C). However, there was no significant difference between the NO expression in cells treated with GIP and control cells in the hyperglycemic condition. To evaluate whether the GLP-1 acts through GLP-1 receptor or not, Exendin (9-39) was used. This determined that the effect of GLP-1 on iNOS and eNOS in HUVEC was reduced significantly compared with treatment with GLP-1 alone. (Fig. 3D).

Effect of GIP or GLP-1 on cAMP concentration in HUVEC. Due to the differing effects of GIP and GLP-1 observed regarding the expression of NO, eNOS and iNOS, the change in the concentration of cAMP was assessed. Increasing GIP concentration in the hyperglycemic condition did not alter the expression of iNOS and eNOS mRNA (Fig. 4A). An increased GIP concentration did not result in any change in cAMP concentration (Fig. 4B). By contrast, it was observed that the expression of iNOS and eNOS mRNA differed significantly depending on the concentration of GLP-1. At higher concentrations of GLP-1 ( $>0.3 \mathrm{nM})$, iNOS mRNA expression decreased significantly $(\mathrm{P}<0.05)$ and at concentrations of GLP-1 $>3$ nM, eNOS mRNA increased significantly $(\mathrm{P}<0.05$; Fig. 4C). Furthermore, cAMP concentration increased in a GLP-1-dependent manner (Fig. 4D). cAMP concentration increased $\sim \mathrm{x} 3$ in hyperglycemic condition ( $30 \mathrm{mM}$ glucose) compared with a normal glucose condition $(5.5 \mathrm{mM})$. The increase in cAMP concentrations following pre-treatment with GLP-1, but not with GIP treatment, indicates that there is an association between the two.

\section{Discussion}

The current study demonstrates that GLP-1 induced cAMP activity serves a pivotal role in GLP-1 mediated vascular protection by increasing NO levels. However, GIP has no effect in GIP associated with increasing cAMP activity in high glucose condition. Thus, the results of the present study 
A

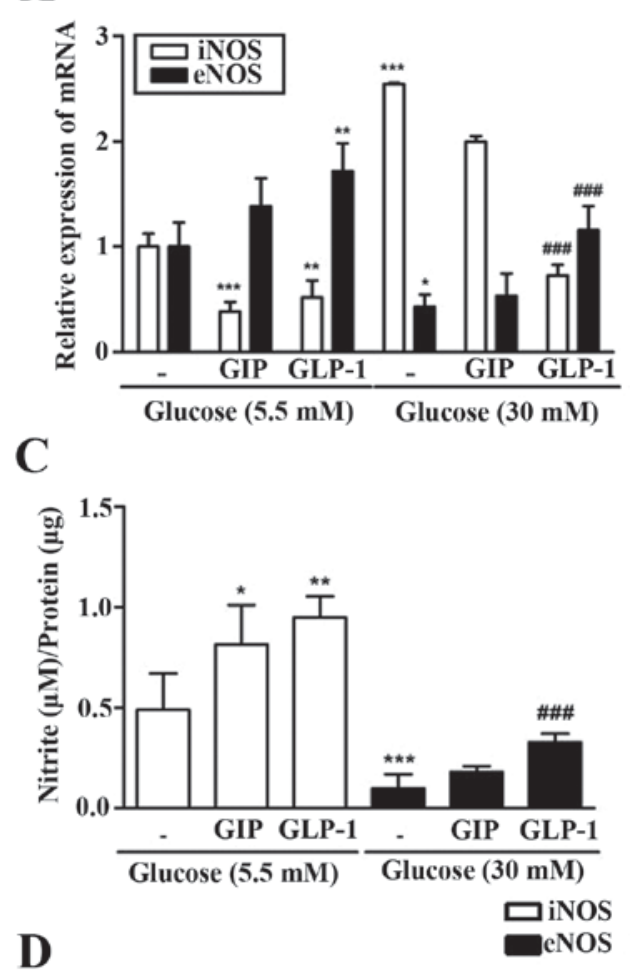

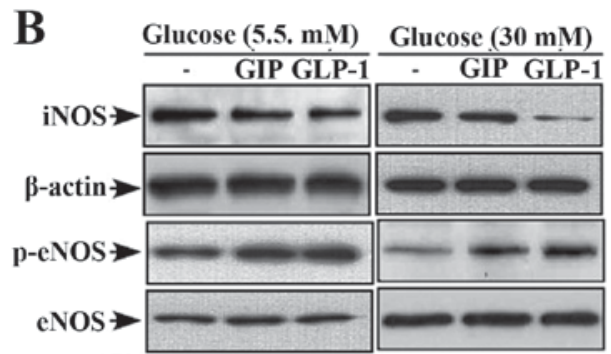
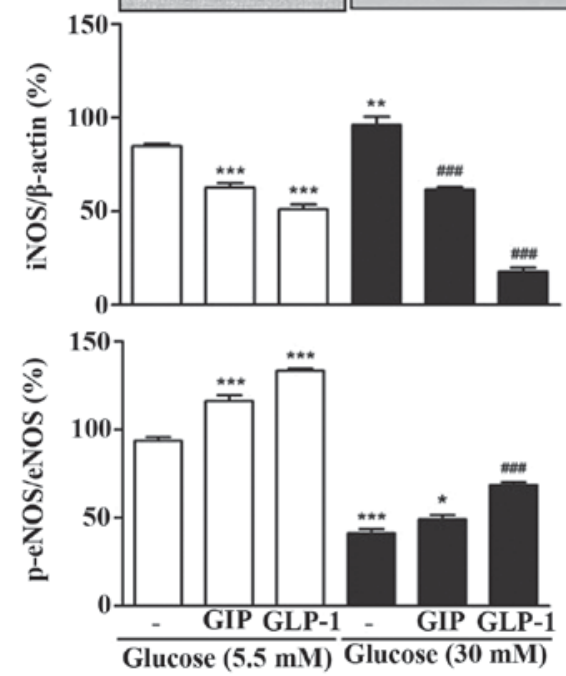

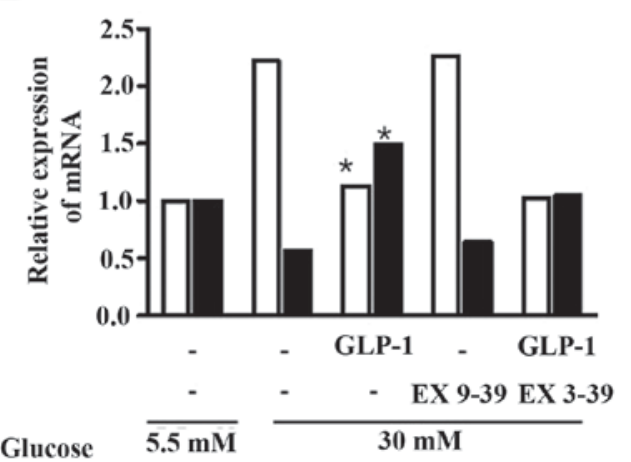

Figure 3. Effect of GIP or GLP-1 on iNOS, eNOS and NO in normal glucose (5.5 mM) or high-glucose (30 mM). (A) Expression of iNOS and eNOS mRNA was determined by reverse transcription-quantitative polymerase chain reaction. (B) Expression of iNOS, p-eNOS and eNOS proteins was determined by western blot analysis. $\beta$-actin was used as a loading control. (C) Activity of NO was examined using a Griess reagent system kit. (D) Following co-treatments with Exendin (9-39), a GLP-1 receptor antagonist, and GLP-1, the effect of GLP-1 on iNOS and eNOS expression in HUVEC was observed to decrease in high-glucose cells (30 mM), compared with treatment with GLP-1 alone. ${ }^{*} \mathrm{P}<0.05,{ }^{* *} \mathrm{P}<0.01,{ }^{* * *} \mathrm{P}<0.001$ vs. control cells of normal glucose $(5.5 \mathrm{mM})$. ${ }^{\# \# \#} \mathrm{P}<0.001$ vs. control cells of high-glucose $(30 \mathrm{mM})$. Data are presented as the mean \pm standard deviation of four independent experiments. GIP, glucose-dependent insulinotropic polypeptide; GLP-1, glucagon-like peptide 1; iNOS, inducible nitric oxide synthase; eNOS, endothelial nitric oxide synthase; NO, nitric oxide; HUVEC, human umbilical vein endothelial cells; p-eNOS, phosphorylated eNOS; DPPIV, dipeptidyl peptidase-4.

indicate that cAMP signaling is required in the protective effect of GLP-1 in endothelial cells.

It has been demonstrated that vascular endothelial cells express GIP and GLP-1 receptors and this has been interpreted to mean that incretin hormones may be useful in the treatment of vascular diseases $(11,12)$. Therefore, the current study aimed to examine how the incretin hormones GIP and GLP-1 act to protect endothelial cells under high glucose conditions and to identify their mechanism of action using a HUVEC cell line.

GLP-1 receptors are widely expressed in pancreatic islets, brain, heart, kidney, endothelial cells and the gastrointestinal tract (13). Some of the functions of GLP-1 in certain organs have been reported but its precise functions have not yet been established (14). Since one of the functions of GLP-1 is to inhibit glucagon and stimulate glucose-induced insulin secretion, it is used as a fasting or postprandial hypoglycemic agent. A protective effect of GLP-1 on vascular endothelial cells has been identified, but its mechanism in endothelial cells remains unknown (13). A previous clinical study demonstrated that GLP-1 may lead to the improvement of aorta pulse wave velocity (PWV) in obese diabetic patients during short-term treatment (15). Aorta PWV is the velocity at which the arterial pulse propagates through the circulatory system and is used clinically as a measure of arterial stiffness (16). It was demonstrated that aorta PWV is directly associated with cardiovascular disease and the early endothelial cell dysfunction marker in patients with diabetes mellitus (17). In the current study, it was suggested that GLP-1 protects against 
A

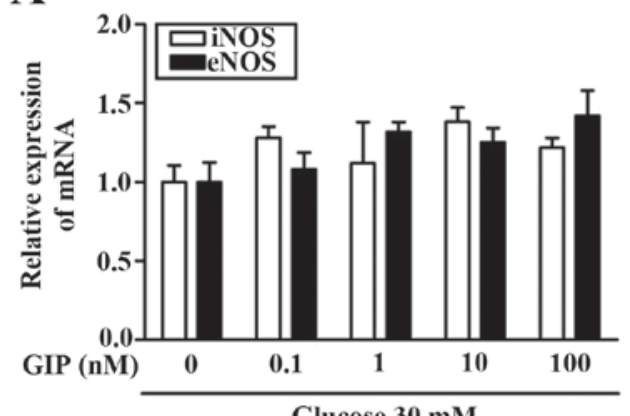

Glucose $30 \mathrm{mM}$

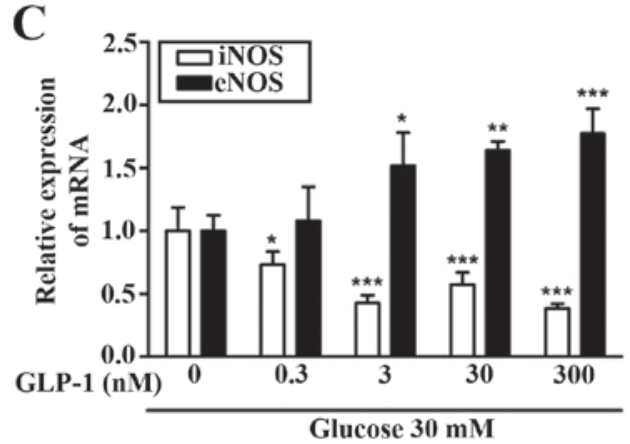

B
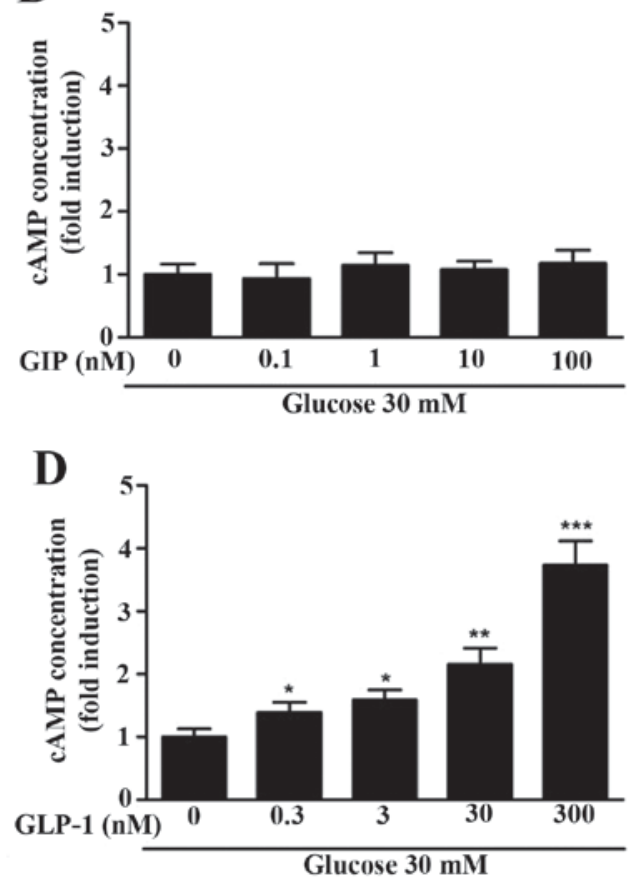

Figure 4. iNOS and eNOS expression and change in cAMP levels according to GIP or GLP-1 dose in high-glucose (30 mM). HUVEC was pretreated with GIP or GLP-1 in the indicated doses and $50 \mu \mathrm{M}$ DPPIV inhibitor for $1 \mathrm{~h}$. HUVEC was maintained in medium containing $30 \mathrm{mM}$ glucose for $48 \mathrm{~h}$. Expression of iNOS mRNA and eNOS mRNA was determined following treatment with (A) GIP or (B) GLP-1 by reverse transcription-quantitative polymerase chain reaction. (C) cAMP concentration was examined following treatment with GIP or (D) GLP-1 using a cAMP EIA kit. ${ }^{*} \mathrm{P}<0.05,{ }^{* *} \mathrm{P}<0.01,{ }^{* * *} \mathrm{P}<0.001 \mathrm{vs}$. control cells of high-glucose $(30 \mathrm{mM})$. Data are presented as the mean \pm standard deviation of four independent experiments. iNOS, inducible nitric oxide synthase; eNOS, endothelial nitric oxide synthase; cAMP, cyclin adenoside monophosphate; GIP, glucose-dependent insulinotropic polypeptide; GLP-1, glucagon-like peptide 1; HUVEC, human umbilical vein endothelial cells; DPPIV, dipeptidyl peptidase-4.

hyperglycemia and vascular endothelial cell dysfunction in hyperglycemic conditions by increasing eNOS expression and thus increasing levels of NO in endothelial cells. This protects the endothelial cells from being damaged by the effects of hyperglycemia. The increase of NO expression in endothelial cells is associated with an increase in eNOS activation by GLP-1, which is dependent on the GLP-1 receptor (18). The results of the present study also demonstrated a GLP-1 dose-dependent increase of eNOS; this effect was significant at low $(5.5 \mathrm{mM})$ and high $(30 \mathrm{nM})$ glucose concentrations. By contrast, the effect of GIP was significant at a low glucose concentration $(5.5 \mathrm{mM} ; \mathrm{P}<0.05)$ but did not cause a significant change in the amount of iNOS and eNOS at higher glucose levels (Fig. 3).

Since the two incretin hormones demonstrated different endothelial cell reactions to a high glucose concentration, the expression of cAMP was measured. The difference in cAMP expression between the two hormones at a high concentration of glucose indicates that GLP-1 is superior to GIP in protecting endothelial cells. Treatment with GLP-1 also resulted in a dose-dependent increase of cAMP occurring. Although the effect of GIP on endothelial vasoconstriction or dilatation may be explained in connection with the types of vascular endothelial cells or the expression of receptors, it exhibits the same result that occurs when blood sugar is controlled normally. As such reactions may be inhibited at high glucose levels due to unresponsive cAMP, GLP-1 is effective even in hyperglycemic conditions.
GIP and GLP-1 stimulate insulin secretion through $\mathrm{Ca}^{2+}$ and cAMP pathways in beta cells (19). In endothelial cells, GIP increases the level of calcium in a dose-dependent manner, however the magnitude of this response differs depending on the endothelial cell type (20). cAMP also increases insulin secretion in beta cells but it inhibits the mitogenic effect and bovine fibroblast growth in endothelial cells (21). By contrast, with GIP, cAMP levels did not increase in endothelial cell lines therefore; the inhibition of cell proliferation caused by cAMP does not occur (22). The results of the present study demonstrated no increase of cAMP upon increasing the GIP concentration at high glucose levels, but GLP-1 increased the cAMP concentration proportional to its concentration. A previous study indicated that there was a significant decrease in proliferation and an increase in the apoptosis of smooth muscle cells in vitro following treatment with exendin-4, this effect appears to be mediated through cAMP signaling (23). Ge et al (24) demonstrated the protective effect of GLP-1 using microvascular endothelial cells whereas the present study used HUVEC as a macrovascular cell line. GLP-1 also protects cardiac microvessels against apoptosis and oxidative stress (24). The protective effects of GLP-1 are dependent on the downstream inhibition of Rho in a cAMP/Protein kinase A-dependent manner (25).

Vascular endothelial cells serve an important function in maintaining vascular homeostasis by controlling vasomotor, blood coagulation and decomposition, and the proliferation and migration of inflammatory cells or vascular smooth 
muscle (26). In patients with diabetes however, hyperglycemia causes endothelial dysfunction and it is difficult to maintain vascular homeostasis. An early complication of diabetes is lesions of dysfunctional endothelial cells, which are initially reversible, however early detection and treatment is required (27). NO is an important factor for endothelial cell dysfunction in the form of lesions that appear in the early stage of vascular disease in patients with diabetes (28). Controlling blood sugar and NO levels in diabetes patients may help prevent and treat vascular complications by normalizing the endothelial function at the early stage of vascular disease (29).

In conclusion, to the best of our knowledge, the present study is the first to identify a dose-dependent association between GIP or GLP-1 and hyperglycemia in HUVEC endothelial cells. This is associated with the generation of eNOS, iNOS and NO at different cAMP concentrations.

\section{Acknowledgements}

The present study was supported by a grant (L.D.M., 2011) from the Korean Diabetes Association.

\section{References}

1. Rask-Madsen C and King GL: Mechanisms of disease: Endothelial dysfunction in insulin resistance and diabetes. Nat Clin Pract Endocrinol Metab 3: 46-56, 2007.

2. ACCORD Study Group; Gerstein HC, Miller ME, Genuth S, Ismail-Beigi F, Buse JB, Goff DC Jr, Probstfield JL, Cushman WC, Ginsberg HN, et al: Long-term effects of intensive glucose lowering on cardiovascular outcomes. N Engl J Med 364: 818-828, 2011.

3. Förstermann U, Closs EI, Pollock JS, Nakane M, Schwarz P, Gath I and Kleinert H: Nitric oxide synthase isozymes: Characterization, purification, molecular cloning and functions. Hypertension 23: 1121-1131, 1994.

4. Wright E Jr, Scism-Bacon JL and Glass LC: Oxidative stress in type 2 diabetes: The role of fasting and postprandial glycaemia. Int J Clin Pract 60: 308-314, 2006.

5. Schäfer A and Bauersachs J: Endothelial dysfunction, impaired endogenous platelet inhibition and platelet activation in diabetes and atherosclerosis. Curr Vasc Pharmacol 6: 52-60, 2008

6. Davignon J and Ganz P: Role of endothelial dysfunction in atherosclerosis. Circulation 109 (23 Suppl 1): III27-III32, 2004.

7. Vilsbøll T, Krarup T, Madsbad S and Holst JJ: Both GLP-1 and GIP are insulinotropic at basal and postprandial glucose levels and contribute nearly equally to the incretin effect of a meal in healthy subjects. Regul Pept 114: 115-121, 2003.

8. Kim W and Egan JM: The role of incretins in glucose homeostasis and diabetes treatment. Pharmacol Rev 60: 470-512, 2008 .

9. Kogire M, Inoue K, Sumi S, Doi R, Yun M, Kaji H and Tobe T: Effects of gastric inhibitory polypeptide and glucagon on portal venous and hepatic arterial flow in conscious dogs. Dig Dis Sci 37: 1666-1670, 1992.

10. Livak KJ and Schmittgen TD: Analysis of relative gene expression data using real-time quantitative PCR and the 2(-Delta Delta C(T)) Method. Methods 25: 402-408, 2001.
11. Ojima A, Matsui T, Maeda S, Takeuchi M and Yamagishi S: Glucose-dependent insulinotropic polypeptide (GIp) inhibits signaling pathways of advanced glycation end products (AGEs) in endothelial cells via its antioxidative properties. Horm Metab Res 44: 501-505, 2012.

12. Forst T, Weber MM and Pfützner A: Cardiovascular benefits of GLP-1-based therapies in patients with diabetes mellitus type 2: Effects on endothelial and vascular dysfunction beyond glycemic control. Exp Diabetes Res 2012: 635472, 2012.

13. Holst JJ: The physiology of glucagon-like peptide 1. Physiol Rev 87: 1409-1439, 2007.

14. Hansotia T, Maida A, Flock G, Yamada Y, Tsukiyama K, Seino Y and Drucker DJ: Extrapancreatic incretin receptors modulate glucose homeostasis, body weight and energy expenditure. J Clin Invest 117: 143-152, 2007.

15. Hong JY, Park KY, Kim BJ, Hwang WM, Kim DH and Lim DM: Effects of short-term exenatide treatment on regional fat distribution, glycated hemoglobin levels and aortic pulse wave velocity of obese type 2 diabetes mellitus patients. Endocrinol Metab (Seoul) 31: 80-85, 2016.

16. Nichols WW: Clinical measurement of arterial stiffness obtained from noninvasive pressure waveforms. Am J Hypertens 18: 3S-10S, 2005.

17. Anderson TJ: Arterial stiffness or endothelial dysfunction as a surrogate marker of vascular risk. Can J Cardiol 22 (Suppl B): 72B-80B, 2006.

18. Ding L and Zhang J: Glucagon-like peptide-1 activates endothelial nitric oxide synthase in human umbilical vein endothelial cells. Acta Pharmacol Sin 33: 75-81, 2012.

19. MacDonald PE, El-Kholy W, Riedel MJ, Salapatek AM, Light PE and Wheeler MB: The multiple actions of GLP-1 on the process of glucose-stimulated insulin secretion. Diabetes 51 (Suppl 3): S434-S442, 2002.

20. Zhong Q, Bollag RJ, Dransfield DT, Gasalla-Herraiz J, Ding KH, Min L and Isales CM: Glucose-dependent insulinotropic peptide signaling pathways in endothelial cells. Peptides 21: 1427-1432, 2000 .

21. D'Angelo G, Lee H and Weiner RI: CAMP-dependent protein kinase inhibits the mitogenic action of vascular endothelial growth factor and fibroblast growth factor in capillary endothelial cells by blocking raf activation. J Cell Biochem 67: 353-366, 1997.

22. Ding KH, Zhong Q and Isales CM: Glucose-dependent insulinotropic peptide stimulates thymidine incorporation in endothelial cells: Role of endothelin-1. Am J Physiol Endocrinol Metab 285: E390-E396, 2003.

23. Eriksson L, Saxelin R, Röhl S, Roy J, Caidahl K, Nyström T, Hedin U and Razuvaev A: Glucagon like peptide-1 receptor activation does not affect re-endothelization but reduces intimal hyperplasia via direct effects on smooth muscle cells in a nondiabetic model of arterial injury. J Vasc Res 52: 41-52, 2015.

24. Ge GH, Dou HJ, Yang SS, Ma JW, Cheng WB, Qiao ZY, Hou YM and Fang WY: Glucagon-like peptide-1 protects against cardiac microvascular endothelial cells injured by high glucose. Asian Pac J Trop Med 8: 73-78, 2015.

25. Wang D, Luo P, Wang Y, Li W, Wang C, Sun D, Zhang R, Su T, Ma X, Zeng C, et al: Glucagon-like peptide-1 protects against cardiac microvascular injury in diabetes via a cAMP/PKA/Rho-dependent mechanism. Diabetes 62: 1697-1708, 2013.

26. Lüscher TF and Barton M: Biology of the endothelium. Clin Cardiol 20 (11 Suppl 2): II3-II10, 1997.

27. Forbes JM and Cooper ME: Mechanisms of diabetic complications. Physiol Rev 93: 137-188, 2013.

28. Deanfield JE, Halcox JP and Rabelink TJ: Endothelial function and dysfunction: Testing and clinical relevance. Circulation 115: 1285-1295, 2007

29. Belz GG and Mohr-Kahaly S: Cacoa and dark chocolate in cardiovascular prevention? Dtsch Med Wochenschr 136: 2657-2663, 2011 (In German). 